\title{
Correction to: A fuzzy rule-based multi-criterion approach for a cooperative green supplier selection problem
}

\author{
Parisa Rafigh ${ }^{1}$ - Ali Akbar Akbari ${ }^{1}$. Hadi Mohammadi Bidhandi ${ }^{1}$. Ali Husseinzadeh Kashan ${ }^{2}$
}

(c) Springer-Verlag GmbH Germany, part of Springer Nature 2021

Correction to: Environmental Science and Pollution Research (2021) 28:14115-14120 https://doi.org/10.1007/s11356-021-17015-2

The correct spelling of the $3^{\text {rd }}$ Author family name is presented in this paper.

Publisher's note Springer Nature remains neutral with regard to jurisdictional claims in published maps and institutional affiliations.

The original article can be found online at https://doi.org/10.1007/ s11356-021-17015-2.

Ali Akbar Akbari

A_akbari@azad.ac.ir

Parisa Rafigh

st_p_rafigh@azad.ac.ir

Hadi Mohammadi Bidhandi

h_mohammadi@azad.ac.ir

Ali Husseinzadeh Kashan

A.kashan@modares.ac.ir

1 Department of Industrial Engineering, South Tehran Branch, Islamic Azad University, Tehran, Iran

2 Faculty of Industrial and Systems Engineering, Tarbiat Modarres University, Tehran, Iran 